\title{
Forward prediction of aeolian systems using fuzzy logic, constrained by data from recent and ancient analogues
}

\author{
Caroline Hern ${ }^{1,2}$, Ulf Nordlund ${ }^{3}$, Kees van der Zwan ${ }^{4} \&$ Kenny Ladipo $^{5}$ \\ 1 Corresponding author; e-mail: caroline.hern@pet.hw.ac.uk \\ 2 Department of Petroleum Engineering, Heriot-Watt University, Edinburgh, UK \\ 3 Dept. Earth Sci., Historical Geology \& Palaeontology, Uppsala University, Sweden \\ 4 SIEP-RTS, EPT-HM, Volmerlaan 8, Rijswijk, the Netherlands \\ 5 NAM, Assen, the Netherlands. Present address: SPDC East, Port Harcourt, Nigeria
}

Received: 30 May 1999, accepted in revised form: 5 June 2000

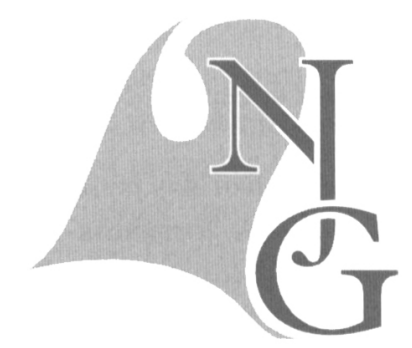

\begin{abstract}
Aeolian sands are the main reservoir rock in some of the largest gas fields, such as the Shell-Exxon Groningen Field, operated by NAM. Although aeolian reservoirs have been studied for many years, there is still room for improvement in the predictive modeling of such reservoirs. A pilot project with this objective was initiated by SIEP B.V. in 1997, together with Heriot-Watt University in Edinburgh, UK and with Uppsala University, Sweden, to evaluate the factors influencing aeolian systems, and to formulate a forward model using 'fuzzy logic'.

The project was initiated to develop a fuzzy system for generic modeling of aeolian architectures. The key aims were to be able to predict the type, amount and distribution of major facies in generic aeolian systems and specifically to model regional-scale architecture in the sub-surface. Fuzzy rules and sets, which defined the behaviour of aeolian systems, were constructed and used to modify the pre-existing fuzzy modeling software which had been designed for shallow and deep marine systems. The modeling procedure used input data appropriate to the Rotliegend climate, and was validated by comparing the resulting models, in terms of thickness and spatial distribution of facies types, to well data from the Upper Rotliegend interval of the Lauwerszee Trough area, NE Netherlands (Figures $1 \& 2$ ).
\end{abstract}

Keywords: Geological modeling, aeolian, fuzzy logic, recent analogues

\section{Introduction}

The Slochteren Formation of the Upper Rotliegend Group forms the main reservoir in the NE Netherlands. The reservoir sands were deposited in a desert plain setting along the edge of the southern Permian Basin. Fluvial deposits, sourced from the Variscan front, dominate the facies to the South and East of the Groningen Block. Major phases of lake expansion from the North resulted in the deposition of the clayrich Ameland and Ten Boer Members, the latter representing the final phase of the Permian Upper Rotliegend sedimentation (Figure 3). The Upper and Lower Slochteren Sandstones lie between these lacustrine transgressions and represent the most northerly advance of the erg during climatic dry phases.

NAM's exploration studies around the Wadden Zee concentrate on areas that were marginal to the Permian desert lake. Facies development and primary reservoir quality are, therefore, major uncertainties. Various geological models have been made throughout the years, many of which are based on sound geological reasoning, but due to the barren nature of the Rotliegend, they all lack a sound chronostratigraphic framework to constrain the correlations.

Depositional modeling, based on understanding the depositional controls, may significantly reduce the associated risks. Ladipo (1997) subdivided the Upper Rotliegend Group according to a sequence analysis 


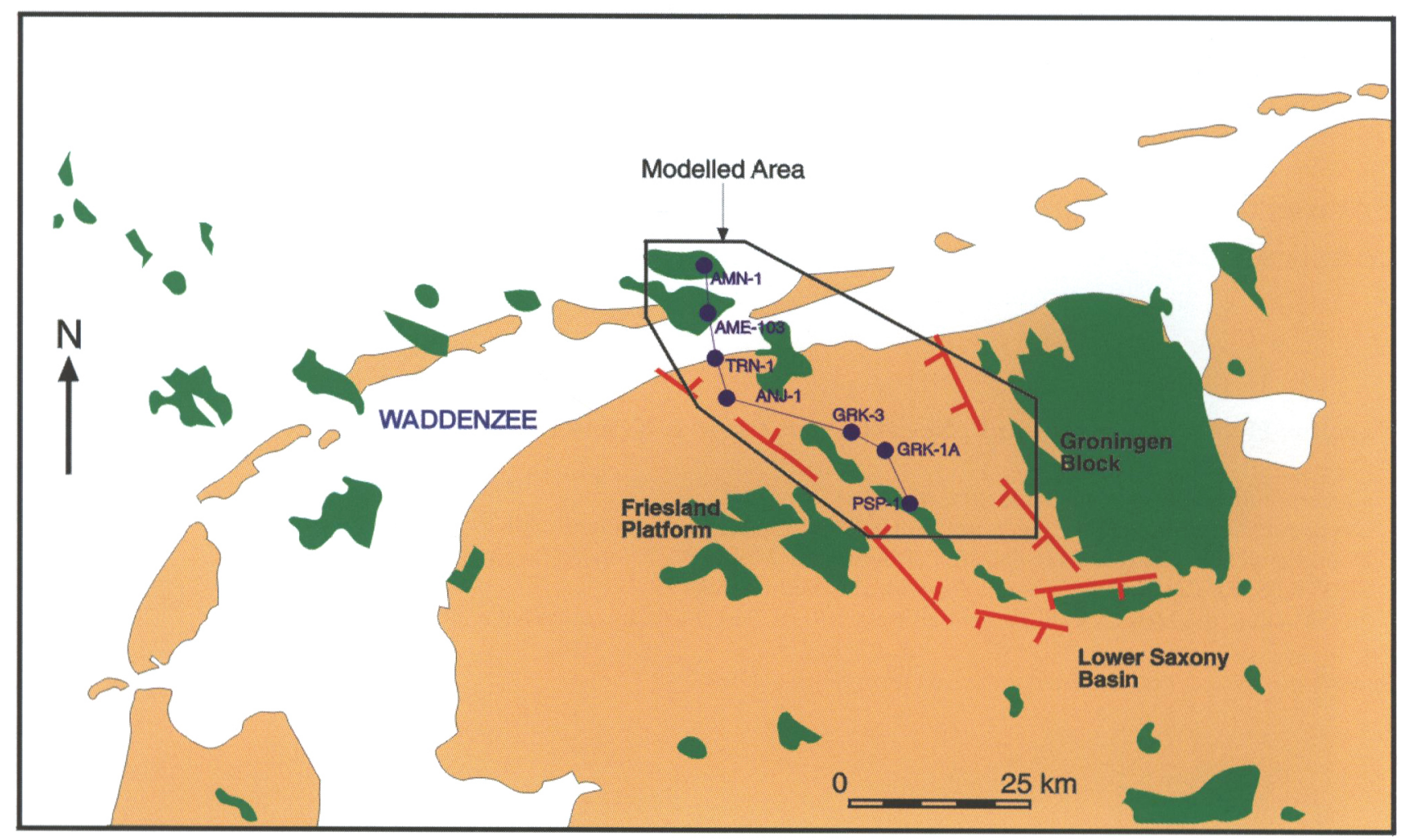

Fig. 1. Location of the study area. Gas fields in green.

approach and constructed a depositional framework using the recognition of facies types and vertical associations, as well as their lateral relationships. The

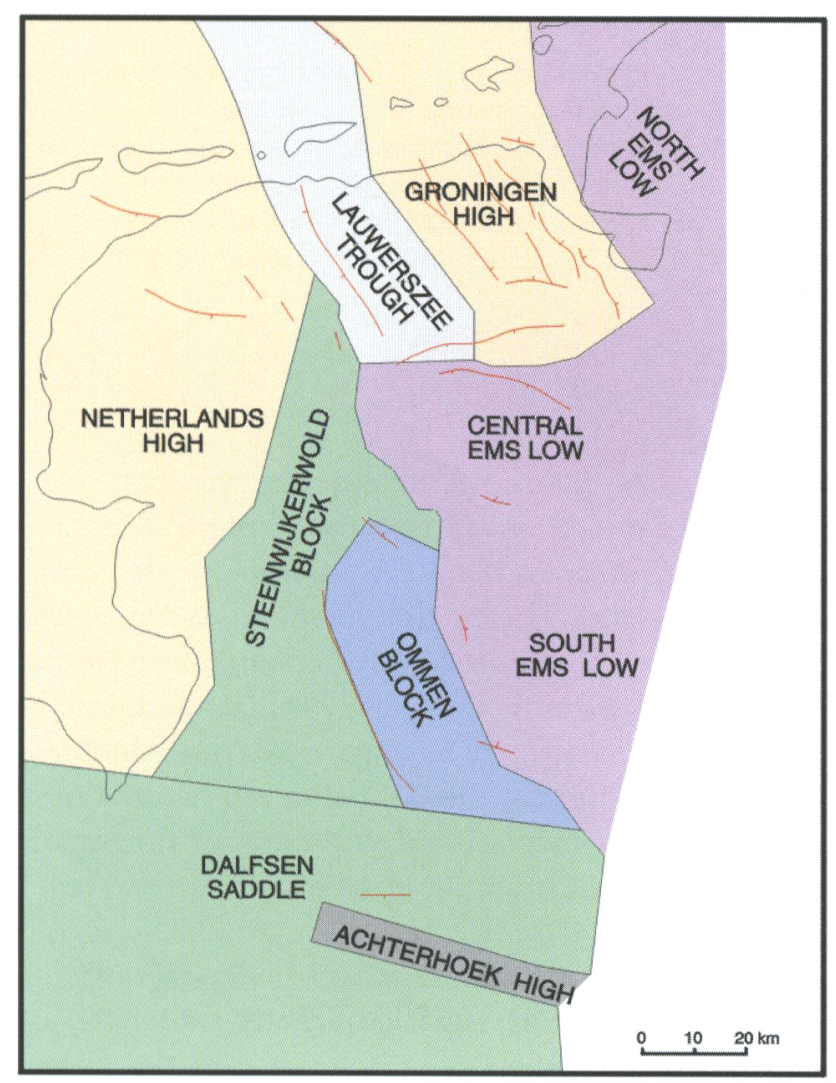

Fig. 2. Main tectonic elements. lithofacies associations and depositional subenvironments identified were grouped into genetic units or cycles. Predictions of the architecture were based on the climatic control of aeolian sedimentation. For example, changes from a dry to a wetter climate were considered to result in an increase in sediment supply and lake-level rise. Aeolian dune formation was considered to be related to the reworking of sands during a dry climatic phase. A consequence of this climatebased model was that shale layers were considered to approximate time lines because they are related to a synchronous change in climate (Figure 4).

Although this model, based on the understanding of geological processes, is very appealing, it has too coarse a resolution to enable reservoir prediction at a useful scale and independent age control is still lacking. To investigate whether it would be possible to predict the distribution of aeolian Rotliegend reservoirs by building a forward model based on controlling geological processes alone, a joint study was undertaken by Shell International Exploration Production B.V. and the Heriot-Watt and Uppsala Universities.

\section{Controlling Parameters}

The architecture of aeolian systems results from the interaction of key variables such as climate, sediment availability, subsidence, and in some cases, eustacy. 

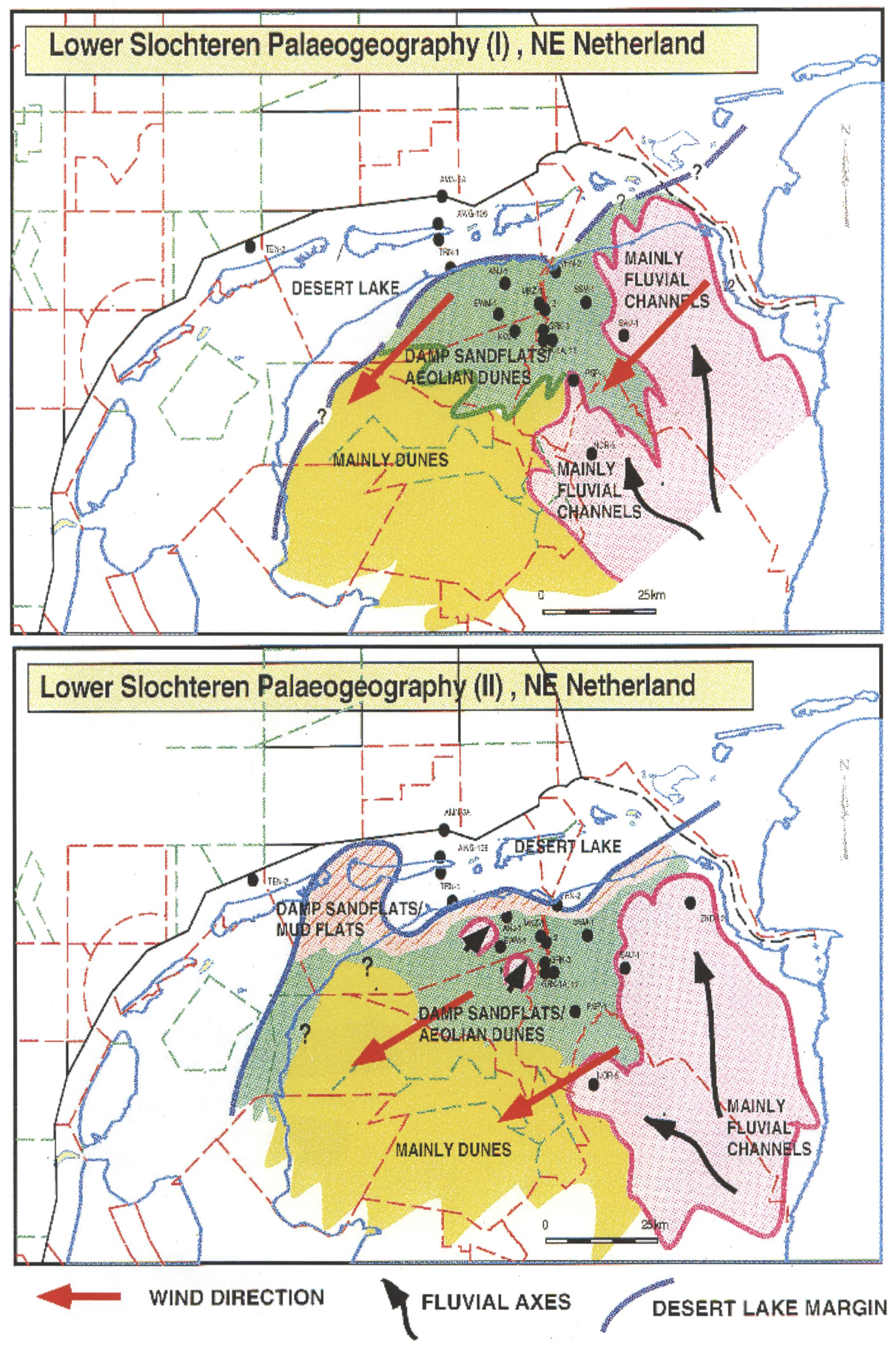

Fig. 3. Paleogeography of the Lower Slochteren Formation. 


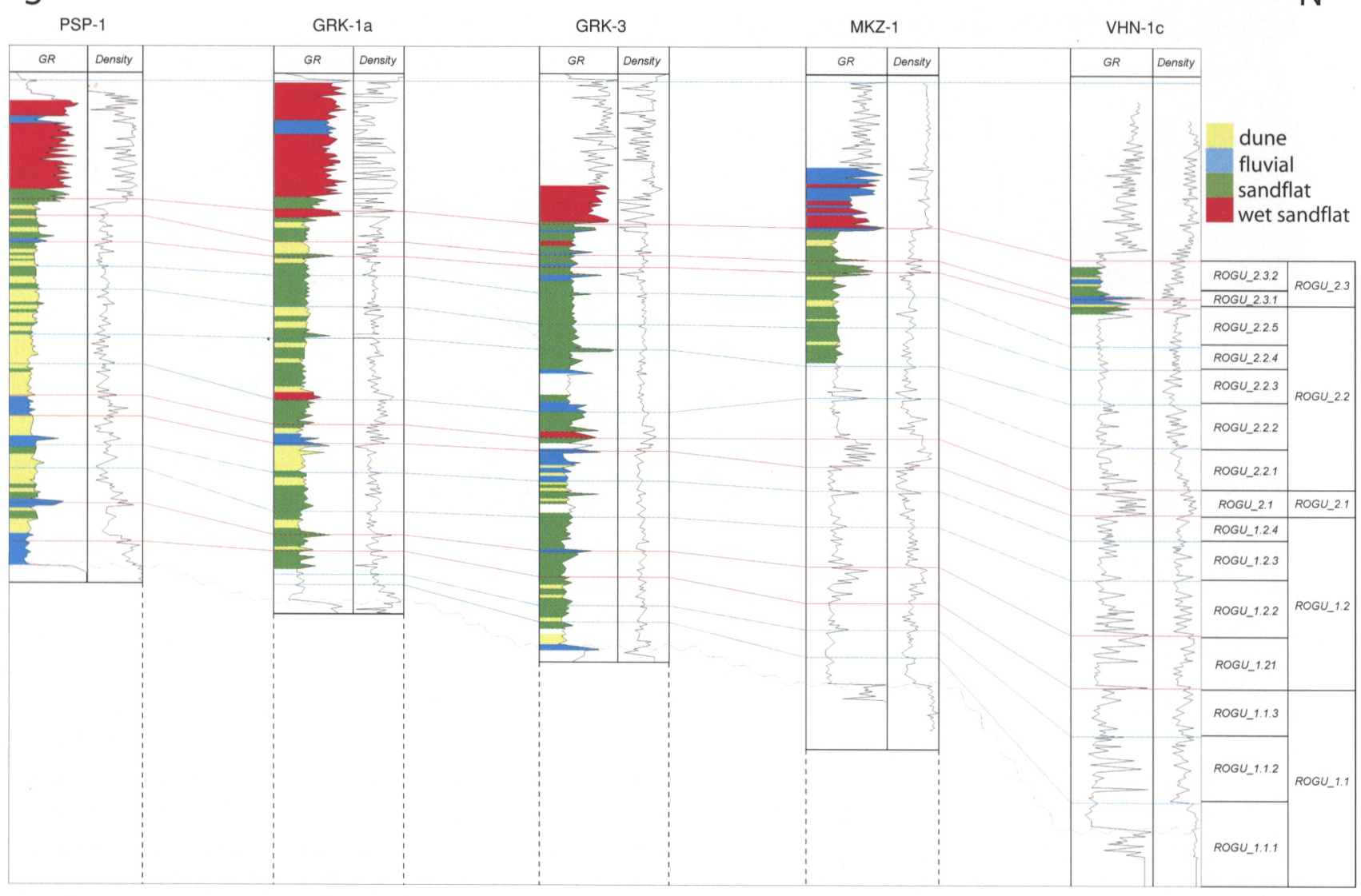

Fig. 4. Regional correlation of Upeer Rotliegend cycles (A) and schematic lake level curve of the Permian desert lake (B).

Each variable changes temporally and spatially, and consequently, so does the relative influence it exerts at a given location and time. Such changes, both in magnitude and influence, are cumbersome to characterize numerically, but are represented very well by fuzzy logic.

Prediction of the architecture of ancient aeolian deposits requires an understanding of the dynamics that control the development of the precursor aeolian system. Today, deserts are formed in arid climates where potential evapo-transpiration exceeds precipitation. Hence, deserts often occur within the zones of tropical high pressure cells, where the descending, stable diverging trade winds are unlikely to produce rain (Figure 5). The aeolian system can be described in terms of the key parameters that act within it, and a comprehensive description requires the characterization of not only these parameters in terms of their minima, maxima, distribution and cyclicity, but also of the interactions that occur between them (Thomas \& Shaw, 1991). Currently, no model exists that unifies the controls together with the processes and responses, although the first principles of aeolian system response are relatively well understood (Kocurek \& Havholm, 1993). In any predictive model, it is therefore neces- sary to determine which are the key parameters, how these parameters change, how they influence the aeolian system (from initial transport through to the final preserved sequence) and how they interact, including any co-dependencies that may exist between them.

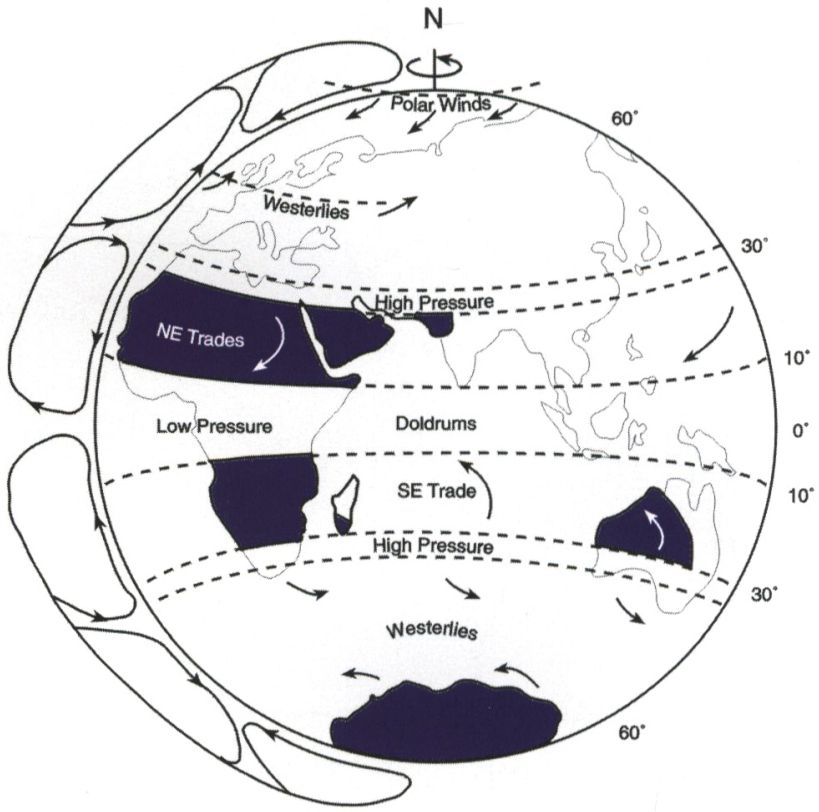

Fig. 5. Location of some of the present-day deserts in the eastern hemisphere. 
Aeolian systems can be divided into three domains that are distinct, based on the processes acting within them and the temporal variation existing between them. These are transportation \& deposition, accumulation and preservation (Kocurek \& Havholm, 1993; Figure 6a \& b). Transportation refers to the movement of silt and sand grade particles by the shearing action of the wind over the exposed surface. Sand grade material saltates, in a layer extending up to a few $\mathrm{cm}$ above this surface, or rolls along the surface. The mode of transportation is determined by the wind velocity and grain size, with movement by saltation being the most common transport process for fine to medium grade sand. Only the silt grade fraction is light enough to be transported in suspension. Sand will not move unless acted upon by a wind that exceeds its threshold velocity, as defined by Bagnold (1941). This threshold velocity is a function of grain density, grain size, surface roughness and cohesion. The latter is a property of the surface and is controlled either directly or indirectly by rainfall.

Deposition occurs when the velocity of the wind falls below the level that is required to keep the grains in motion. Initiation of deposition often occurs at minor irregularities that increase the shear drag such as vegetation, animal remains, bioturbation or patchy precipitation of salts on the surface. Once deposition has been initiated, dunes commonly develop. In areas of

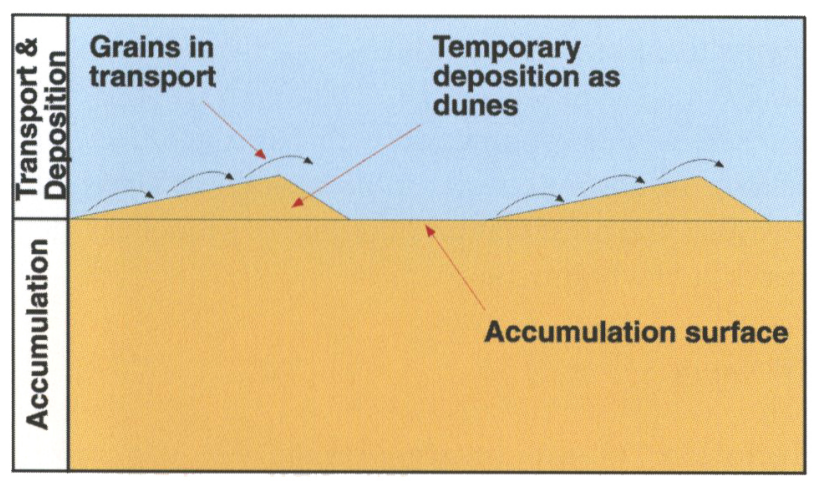

Fig. 6a. Transport \& accumulation domain.

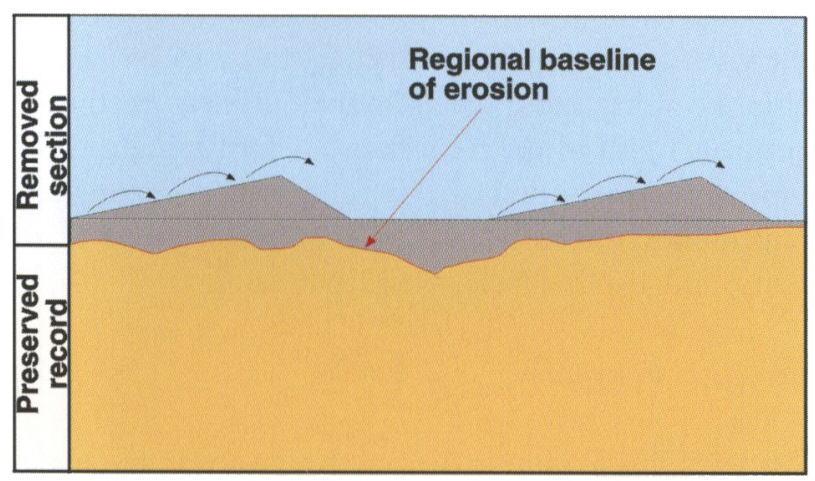

Fig. 6b. Preservation domain. low wind energy, for example, where regional airflow is decelerating or diverging (Wilson, 1971), deposition is concentrated and dunes aggregate to form sand seas (Fryberger \& Ahlbrandt, 1979).

Accumulation is defined as net deposition through time, and an accumulation is separated from the sediment in transport above it, by a surface that joins successive dune troughs together (Kocurek \& Havholm, 1993). Preservation occurs when the accumulation is placed below the regional baseline of erosion and is incorporated in the rock record (Kocurek \& Havholm, 1993). Factors that favour preservation include subsidence and a rise in the level of the water table, whether absolute or relative.

\section{Factors Influencing Aeolian Systems}

From experience with 2D forward modeling (De Jongh, 1996; Fonseca, 1999), it may be deduced that only four main controlling parameters determine the stratigraphy in a coastal marine setting: subsidence, topography, eustatic sea level and sediment supply. Subsidence is determined by large-scale tectonic movements, which create the accommodation space required to preserve deposits. Topography determines the local distribution of facies. Eustatic sea level, in conjunction with subsidence, influences accommodation space and small-scale variations in sediment distribution and can be directly linked to the eustatic sea-level curve of Haq et al. (1988). Sediment supply is governed mainly by variation in climate and tectonic activity.

The controlling parameters deduced for the aeolian model are by and large the same as those for the coastal marine setting. The only difference is that the sea-level curve is replaced by a lake level curve, which is governed by climatic variation. Climatic factors also play an important role not only in sediment supply, but also in redistribution of sediment under the influence of the wind. A short review of the influence of key factors is given below.

\section{Wind}

At a regional scale, wind is the movement of air from a region of higher pressure to one of lower pressure. This can be predominantly horizontal, such as in trade wind belts, or vertical, due to adiabatic convection. Wind controls the spatial and temporal distribution of dry sand and silt-sized particles. The sediment saturation of the wind determines whether it transports, deposits or erodes. For simplicity, the erosive 
capacity of the wind in AEOLIAN FUZZIM is treated as proportional to velocity.

\section{Rainfall}

Effective precipitation is defined as the amount of rainfall that exceeds evaporative loss. Rainfall in the contemporary desert environment exerts an effect in three main ways:

- By determining the amount and frequency of sediment input to the receiving basin, and its transport pathway via rivers etc.

- By increasing the threshold velocity either directly, by dampening the desert surface and increasing cohesion between grains (Arens, 1996, Nickling, 1978), or indirectly, by promoting growth of vegetation which significantly increases the surface roughness. Under contemporary environmental conditions, dune fields are commonly regarded as inactive due to the stabilizing effects of vegetation cover, in regions where the annual precipitation is greater than $150 \mathrm{~mm}$ (Wiggs et al., 1995).

- By partly controlling the level of the water table.

\section{Temperature}

Temperature is defined as the state of hotness or coolness of a body, in this context, the atmosphere and surface of the earth. Temperature variations in the atmosphere and surface of the earth result from differential insulation by sun. Temperature influences the aeolian system in two ways; it controls the viscosity of the air, indirectly affecting the sediment carrying capacity of the wind, and in conjunction with the wind, controls the rate and amount of evaporation.

\section{Source and supply}

In this context, source is defined as the sediment that enters a basin. In aeolian systems, the primary source of sediment is alluvium (Cooke et al., 1993, Williams \& Lee, 1995). Sediment is generated from the erosion of hinterland areas and transported into the basin as either debris flows on alluvial fans (typical in arid climates) or as bed load within (ephemeral) river systems in more humid climates. Sediment supply is the amount of sediment released for transport into the basin. It is strongly correlated to rainfall, but may be partly affected by tectonism, which can increase the amount of sediment generated, by uplift and rejuvenation of the hinterland.

The reworking of previously deposited sand provides secondary sources of sediment. These sources may be adversely affected by changes in base level, as the sediment within the capillary fringe of the water table tends to be trapped due to the increased cohesion. Such base level changes may result from increased rainfall, sea level rise or subsidence. In the Rotliegend, secondary sources of sediment to the East were frequently trapped by rises in level of the Silverpit Lake, which fluctuated in response to glacially driven climatic wettening (Glennie et al., 1994).

\section{Basin Topography}

Basin topography is defined as the shape of the basin. This controls the location of alluvial sediment input and provides accommodation space for deposition (Kocurek \& Havholm, 1993). In addition, basin topography determines areas of regional flow divergence or convergence, which in turn, controls the location and activity of aeolian accumulations (Wilson, 1973).

Topography also influences precipitation. Climatic modeling by Kutzbach \& Ziegler (1994) shows a conspicuous increase in rainfall levels that are associated with orographic elevations. Such orographic rains do not occur if the modeled surface remains flat.

\section{Subsidence}

Subsidence is the progressive sinking of a basin. Subsidence can vary temporally and spatially and the rate at which it does so is controlled by tectonic readjustments to crustal stress patterns.

Subsidence, in conjunction with basin geometry and relative or absolute water table variations, largely determines the preservation potential of sequences (Kocurek \& Havholm, 1993).

\section{Tectonism}

Tectonism is the process responsible for crustal movements. It varies both spatially, controlling relative activity of areas, and temporally, with slow movements requiring geological time scales to be noticeable, to very rapid catastrophic events. Tectonism controls uplift in the hinterland, determining the volume of sediment that can be generated, compartmentalization of the basin into areas of quiescence and activity, and also controls subsidence rates.

\section{Sea Level Fluctuation}

Sea level fluctuation is the relative or absolute change in mean sea level, and this varies over geological time 
scales. A number of factors influence changes in sea level, for example, the growth of glaciers (Marsh \& Ditlevsen, 1997) which results in rapid, high magnitude ( $\mathrm{cm}$ per year), global changes, or changes in the volume of ocean ridges, which results in slow, low magnitude, changes. Spatially, absolute changes in sea level are global in extent, but relative changes may be more local in extent, for example if influenced by subsidence on a passive margin.

Sea level may influence aeolian systems in numerous ways. Changes in sea level may alter the area available for source generation, as in the Permian Cutler Formation of SE Utah (Loope, 1985). Sea level, in conjunction with subsidence, may also be important in some systems by contributing to water table fluctuations and, in so doing, control accommodation or preservation space.

The Rotliegend basin was ostensibly land locked. Glacially driven changes in sea level and the periodic marine flooding of the basin associated with interglacial high stands, are however, thought to have altered the size of the lake and thus controlled the area available for generation of secondary sediment sources (Glennie et al., 1994).

\section{Driving Mechanisms}

Variations in the earth's orbital parameters are thought to be responsible for climate and sea level fluctuations. The variation in orbital parameters controls the amount of solar insulation received by Earth's surface (Imbrie \& Imbrie, 1979). One of the major effects of this in conjunction with plate configuration is the initiation and collapse of glaciations. Glaciations occur during periods of low-level insulation that result in a net cooling of the Earth's surface. The intensity of glacial periods depends on the magnitude of the orbital variation, but this can be enhanced considerably by plate configuration and is especially pronounced when plates overlie either pole, as in the Permian (Figure 7). Because much of the water is held as snow, glacial periods are typically arid and times of low sea level, whilst interglacials are, conversely, humid and of high sea level. Often, although not exclusively, periods of desert formation are associated with arid climatic conditions induced by high-latitude glaciations.

Different parameters of orbital variation give rise to four nested cycles of distinct frequencies (Figure 8) where frequency is generally regarded as inversely proportional to the climatic effect (Perlmutter \& Matthews, 1989). As the orbital cycles, either directly or indirectly, drive variations in the parameters listed above, temporal changes in these parameters are likely to occur at frequencies defined by the orbital cycles.

\section{Fuzzy Logic}

In conventional, two-valued (or crisp) mathematical logic, only two states are allowed, true or false. That is, an object either is, or is not, a member of a particular set. There is no room for uncertainty. This rigidity means that conventional logic is less suitable for handling vague and ambiguous information, such as qualitative geological knowledge.

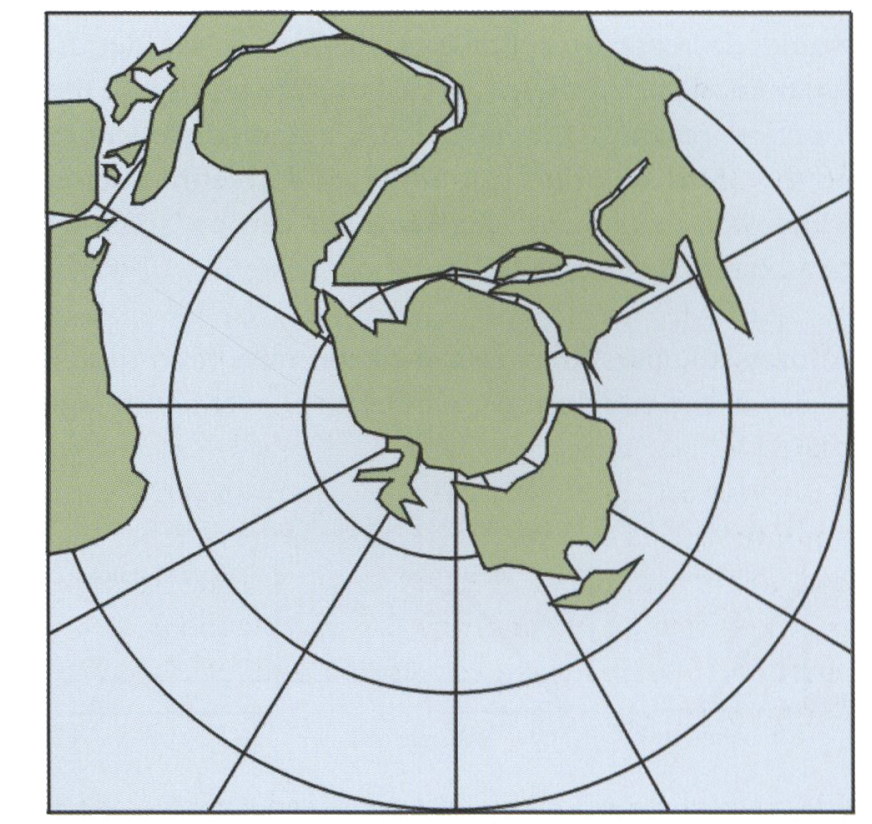

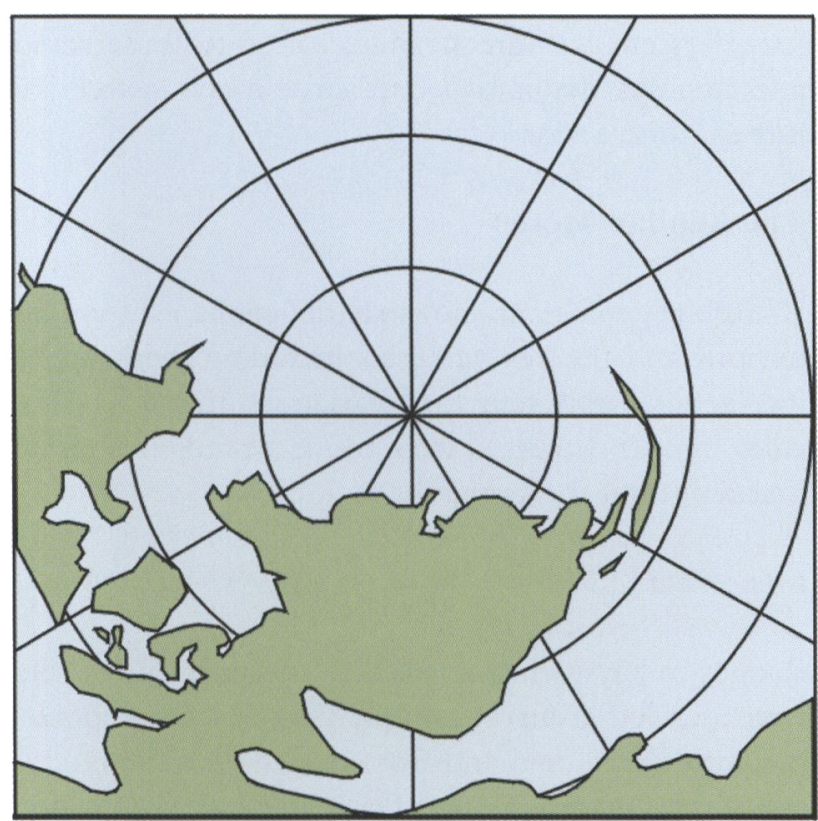

Fig. 7. Location of the continental plates during the Sakmarian stage. On the left the North Pole and on the right the South Pole. 


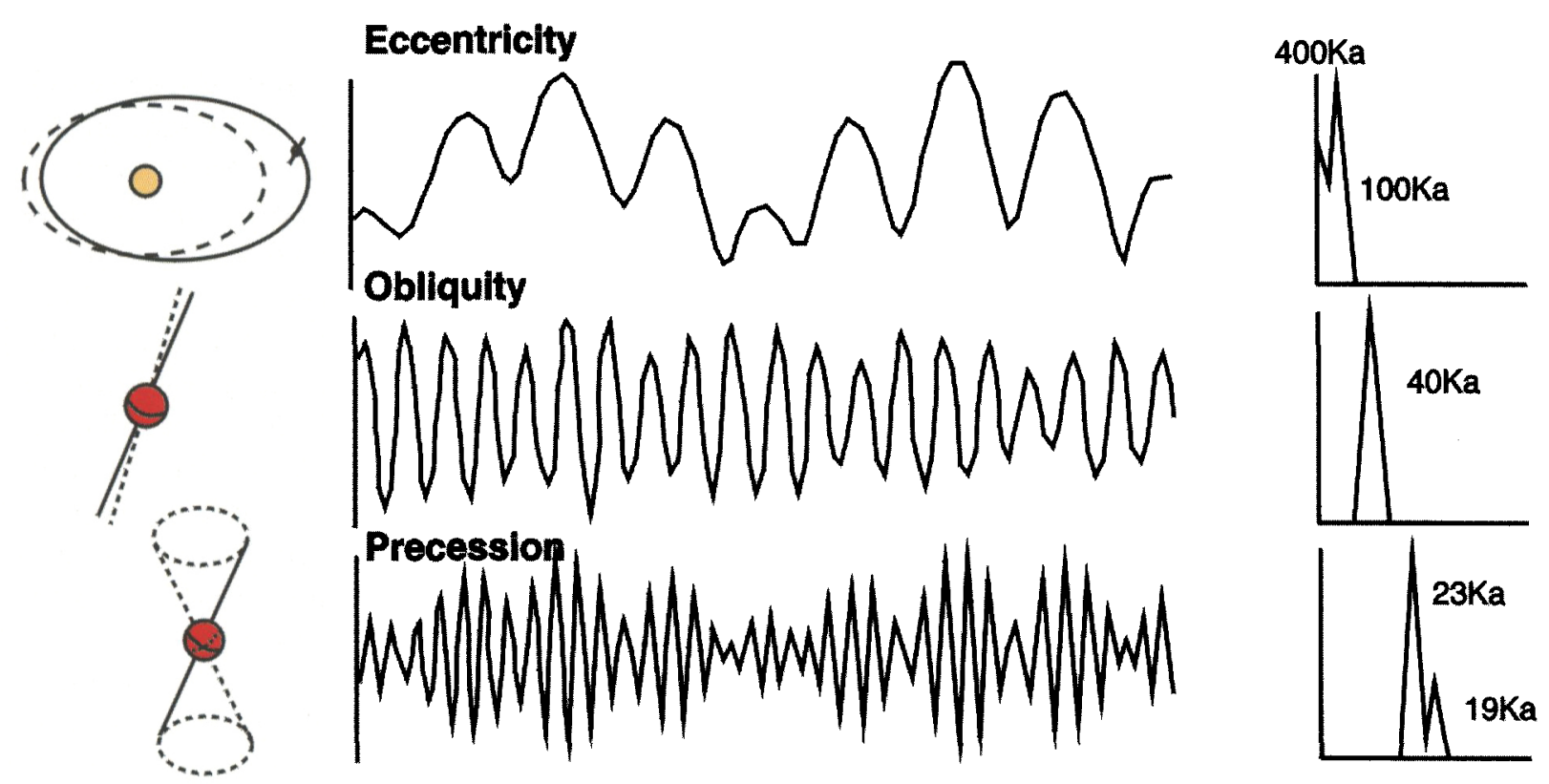

Fig. 8. Major orbital cycles.

Zadeh suggested a more general form of logic, called 'Fuzzy Logic', in the 1960's (Zadeh, 1965). This new approach allowed for definition of partial memberships, which not only opened up possibilities for formal definition and analysis of qualitative information, but also allowed for very efficient treatment of complex non-linear relationships.

The fundamental concept in fuzzy logic is the fuzzy set (Figure 9). The membership values for a fuzzy set are defined by a membership function, a curve based on some, usually continuous, domain variable. A fuzzy set 'shallow', for instance, would have a membership function close to 1.0 (true) for very shallow depths (immediately below the water surface), which would decrease as depth increased. At some depth, say $80 \mathrm{~m}$, it is definitely not shallow any more and the function reaches 0.0 (false). An intermediate depth of, say $35 \mathrm{~m}$, will thus not be forced into either being 'shallow' or not being 'shallow', but can be 'shallow' to a certain degree, say 0.85 .

A fuzzy rule uses fuzzy sets in the premise (and usually also in the conclusion). Similar to conventional log-

IF shallow AND near river THEN deposit much

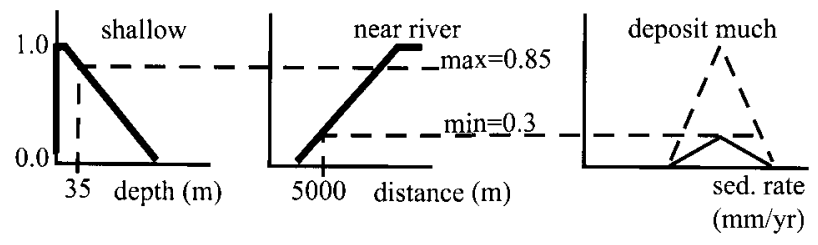

Fig. 9. Graphic of a fuzzy rule using the AND-operator (conjunction). ic rules, the truth of the premise determines the truth of the conclusion. But because fuzzy sets are used, the conclusion does not have to be either true or false. It can also be true only to a degree. The truth of a rule with more than one fuzzy set in the premise is determined by the lowest truth-value when the operator is 'AND' (conjunction), and by the highest value when the operator is 'OR' (disjunction).

A collection of fuzzy rules applied to a particular problem is called a fuzzy system. The output from a fuzzy system is a compromise between the conclusions from all rules executed in parallel. A fuzzy system can be regarded as analogous to a collection of equations, which together are capable of solving complex non-linear problems. The difference is that a fuzzy system is more flexible, easier to understand, and handles qualitative data in a much better and more intuitive way.

\section{The Aeolian Model}

Using the geological knowledge of aeolian system behaviour and the key variables including their ranges, interactions and temporal variation, fuzzy sets and rules were constructed to produce a predictive model that replicates the system behaviour.

\section{Input Data}

Ranges in key variables, used to construct fuzzy sets, were derived from a combination of contemporary meteorological data and from palaeo-climatic modeling of the Quaternary and Permian. Each data source has associated advantages and disadvantages. 
Contemporary meteorological data, although attractive due to its abundance, detail and certainty, it is of limited use, as it reflects our present interglacial conditions. Many of the world's ancient desert systems, and certainly those of the Permian, were deposited during glacial periods, when both the northern and southern hemispheres were under the influence of high latitude ice sheets. The high-pressure systems, which developed over the poles, compressed climatic belts, resulting in an increase in average wind velocity at trade wind latitudes. In addition to variation in glacial and interglacial wind velocity, the temporal distribution of velocity may also have been different and it is likely that the stronger glacial winds blew for longer periods of the year. In consequence, during glacial periods, the potential for moving sand was much greater.

Data calculated from Pleistocene glacial periods, such as temperature (deduced from $\ddot{a}^{18} \mathrm{O}$ analysis of ice cores), wind speeds and rainfall; at least provide a more realistic basis for comparison. However, the distribution of land areas in the Permian was vastly different to that in the Quaternary. This would have influenced temperature, rainfall and wind patterns as a result of spatial differences in insulation.

Palaeo-climatic modeling provides the third data source. These models provide quantitative estimates of a wide array of climatic variables (temperature, cloudiness, wind strength and direction) at high temporal resolution (daily) and geographical completeness. The method has the advantage of simulating the correct landmass distribution, but, like all models, it is dependant to an extent on the input variables. Further disadvantages of such data include the current inadequate parameterization, over-simplistic algorithms, primitive coupled atmosphere-ocean systems, and technological limitations with respect to the required computer power (Allen et al., 1994). Nevertheless, the data from such models provide a useful constraint on the key parameter input values derived from alternative sources.

In addition to the variable ranges from the data sources above, other variables were necessary in order to characterize the system. These included a topographic surface (Top Carboniferous), a basic subsidence curve and wind directions for the Lower and Upper Slochteren Sandstones. Each of these variables was sourced from analysis of the subsurface data.

\section{Model Construction and Behaviour}

The program 'AEOLIAN FUZZIM' is a 3D stratigraphy forward modeling tool, using fuzzy systems in- stead of equations, to determine where and when sediments should be deposited or eroded. It takes, as input, a pre-defined initial surface, together with curves describing changes in external variables such as temperature, rainfall, subsidence, etc. It produces, as output, a stratigraphic model in $3 \mathrm{D}$. The stratigraphy is the result of repeatedly applying a hierarchy of fuzzy systems. The rules in these systems are based on geological knowledge and the modeling process can be thought of as repeatedly, for each position on the depositional surface, performing a sedimentological interpretation given the current conditions.

Part of the rule base in 'AEOLIAN FUZZIM' first subdivides the depositional surface into four main depositional environments: fluvial, erg, sabkha and lake. These are based on variables such as rainfall, temperature etc. Note that the environments are represented by fuzzy sets and that a certain position can consequently be wholly or partly a member of more than one environment, this is obviously also the case in real life. An example of a typical rule would be: 'IF near lake AND high water table THEN sabkha'.

After having defined environments, the program then applies a collection of rules using, among other things, environment-based sets in the premise. A typical rule would be: 'IF erg AND high wind velocity AND leeward position AND NOT steep slope THEN deposit much AND medium sand'. The geological reasoning here is obvious. This transparency is, in fact, one of the main advantages of using a fuzzy system.

Figure 10 shows an example of the result from a complete modeling run using a total of 53 rules. Here, a periodicity in rainfall and wind velocity causes a cyclic deposition pattern with erg sediments representing dry times and fluvial/lake sediments representing wet. The lateral distribution of different sediment types during one climate cycle is shown in figure 11 .

Using this configuration, the model behaved as expected. In a wet climatic phase, the fan progrades from the alluvial source. At the same time the lake transgresses and increases in size. Aeolian transport and deposition cease. During dry climatic conditions, aeolian deposition is initiated. The fan area recedes, lake level falls and the erg progressively expands over the area. Grain size varies with proximity to the source and wind velocity and the amount of sediment deposited varies with rainfall and proximity to source. Key erosion surfaces (potentially correllatable features in the subsurface) develop at peak wind veloci- 

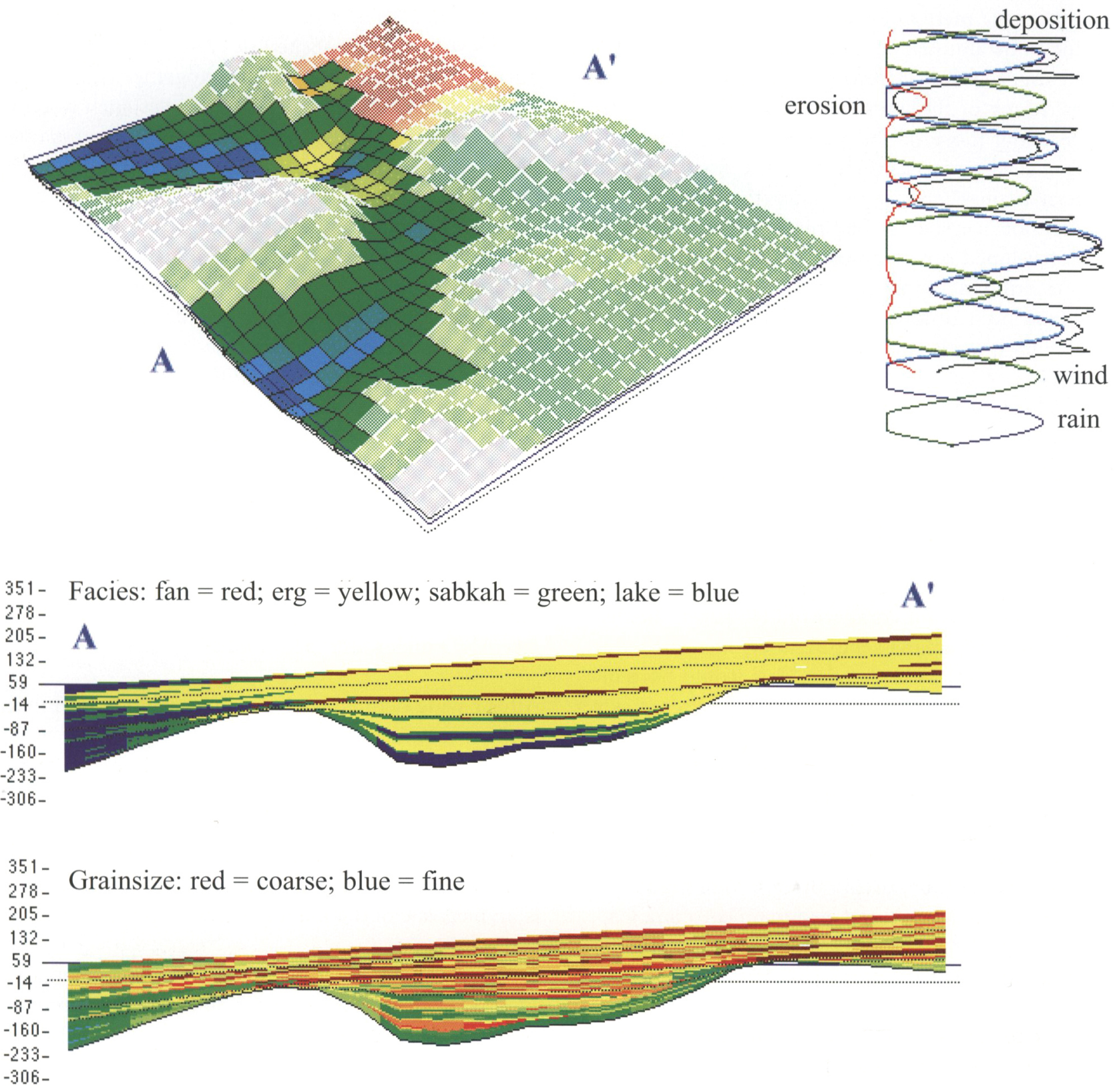

Fig. 10. Original model with all parameters allowed to vary as presecribed.

ties. The magnitude of erosion varies spatially, depending on the orientation of the topographic features with respect to the wind direction, so that erosion is greatest on windward slopes and highs and less in protected leeward areas.

\section{Testing the Model}

Using the input data described, the fuzzy system modeled the Rotliegend successfully. However, to ensure that we were not mimicking the data without making universal rules, the relative importance of each parameter was evaluated in a series of tests. The model was tested using two procedures; one to run simulations with parts of the controlling system re- moved and the other by feeding extreme values, replicating the worst case scenario. The tests showed that the following parameters are the most important: climate, subsidence and surface topography.

\section{Shutting off systems}

As the model is divided into depositional subsystems, switching these systems off allows the validity of the rules governing each system to be checked.

When the simulation is run using only the fan rules, effectively removing the aeolian system (transport, deposition and erosion), fluvial sediments dominate and their geometries constitute a simple and pre- 


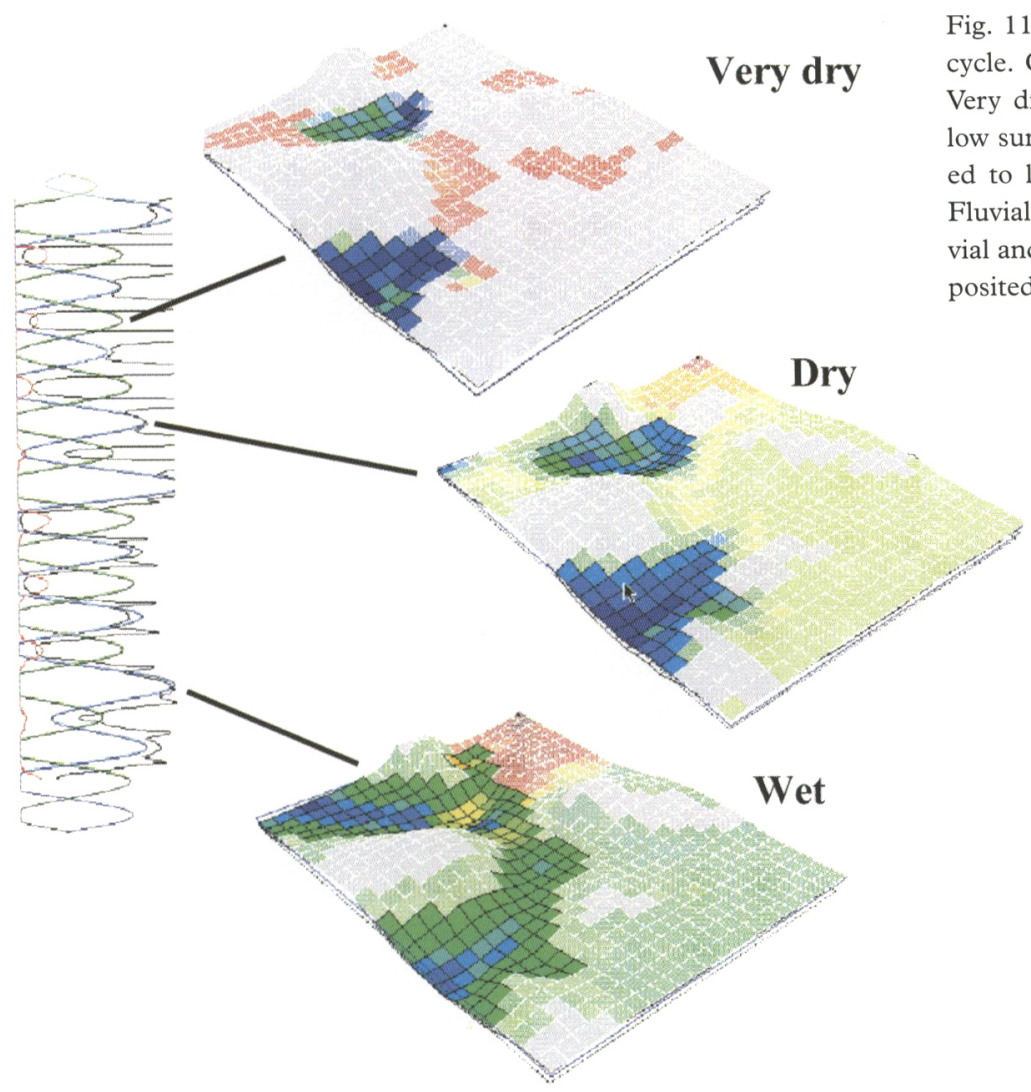

Fig. 11. General behaviour of the model during one climatic cycle. Colours represent grain size:red $=$ coarse; blue $=$ fine. Very dry: Extensive erosion due to high wind velocities and low surface stability. Deposition of coarse sediment is restricted to leeward locations. Dry: Aeolian deposition dominates. Fluvial is limited and the lake level is low. Wet: Extensive fluvial and sabkna deposition. In the lake, coarser sediment is deposited near the store.

dictable wedge that thins distally from the source (Figure 12). Depositional rates and lateral extents are tied to the rainfall curve, so that they are greatest during peak rainfall. Sediments infill topographic lows, since the fan area is limited by the restriction that fluvial sediments are not allowed to travel upslope.

In the opposite case, where only the aeolian rules are used, but without triggering surface morphology and wind direction rules, the result is an isopachous deposit of aeolian sand that covers all surfaces above the level of the water table (Figure 13). Under the same conditions but including the surface morphology and wind direction rules, differential deposition controlled by wind direction is obvious, as sediment

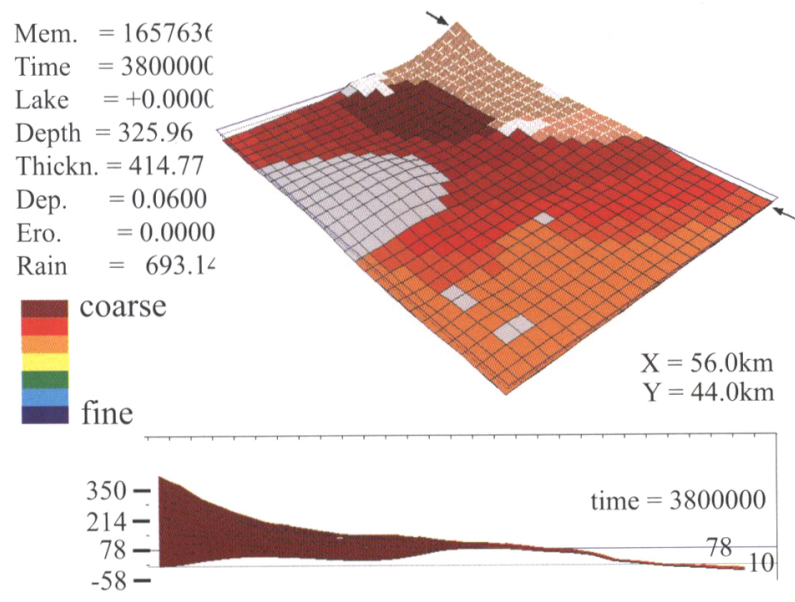

Fig. 12.3D model and cross section simulated using fan rules only. is trapped on leeward slopes and eroded on windward slopes (Figure 14).

Using only the lake rules allows lake behaviour to be assessed. It shows that deposition varies as a function of lake level in as much as sediment fills the accommodation space available and can deposit up to the lake surface in shallow areas (Figure 15). Grain size decreases away from the shore and evaporite precipitation occurs at the lake center during peak aridity.

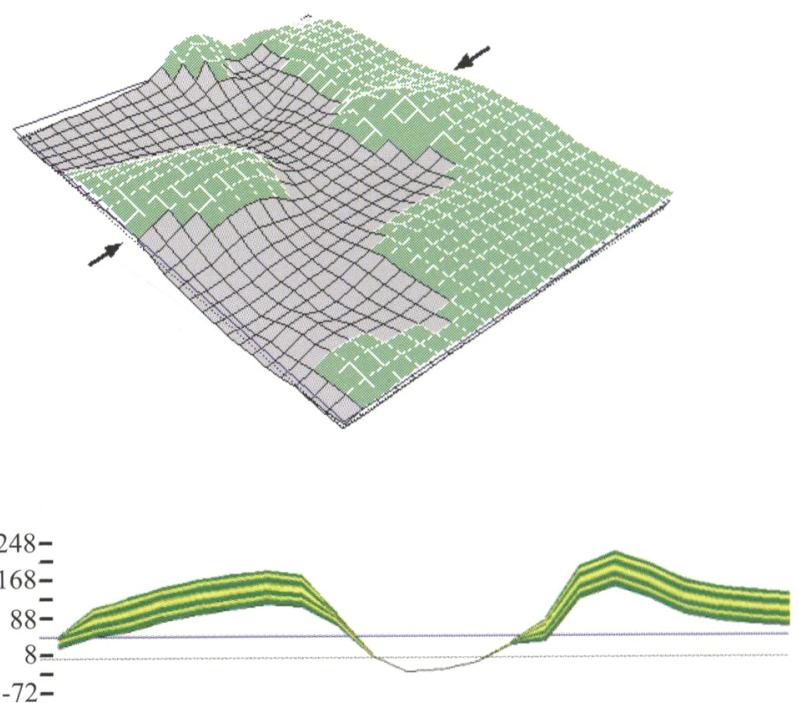

Fig. 13. Simulation using aeolian rules only but without surface morphology and wind direction rules. An isopachous layer of sand forms everywhere above the water table. 

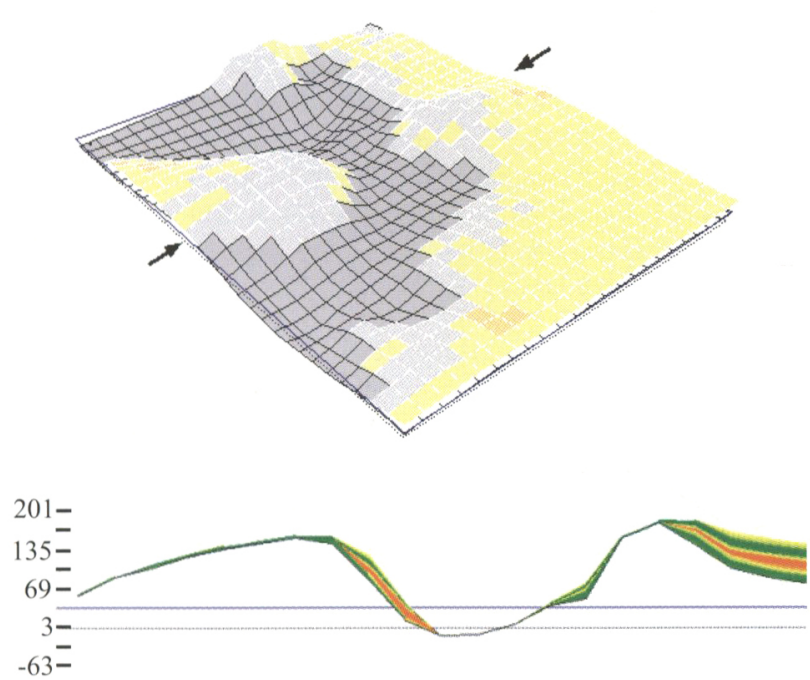

Fig. 14. Simulation using aeolian rules only, but with surface morphology and wind direction rules. Sediment is trapped on leeward slopes and eroded on stoss slopes.

\section{Constant input variables}

In these tests, input values for wind velocity and rainfall are kept constant, which although not very realistic, enables an assessment of how the system handles extreme situations.

If, for instance, wind is 'shut off' (i.e. wind speed is set to 0 ) no deposition occurs on highs and there is no trapping of sediment in leeward positions (Figure 16). These differences are logical and easy to explain: there is no deposition on highs because without the wind there is no mechanism for transporting sedi-
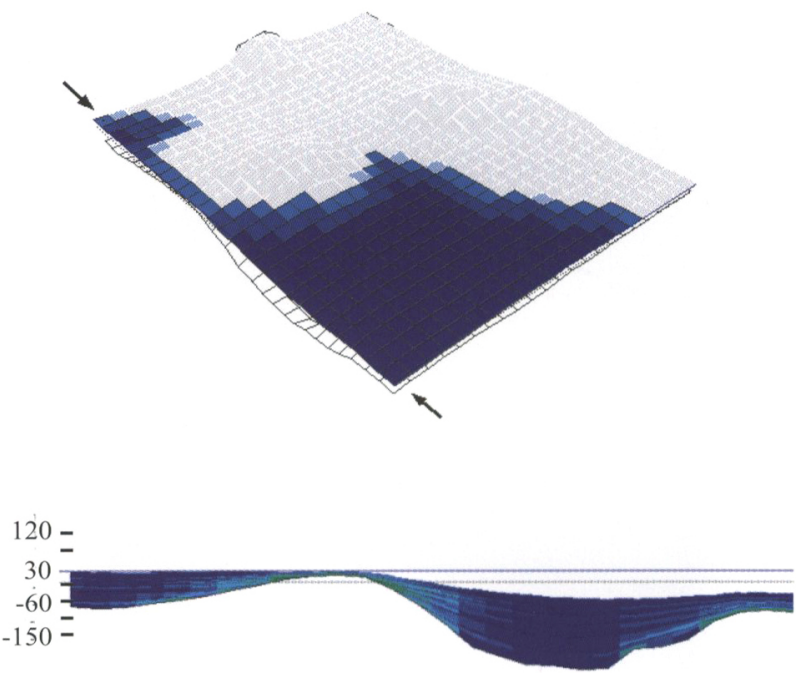

Fig. 15. Map: Simulation using lake rules only. Profile: Deposition occurs up to water level; grain size decreases distally from shore.

ments up-slope, and there is no trapping of sediment in leeward positions because 'leeward' is not defined in the absence of wind.

With a constant wind velocity of $5 \mathrm{~m} / \mathrm{s}$, extensive aeolian deposition results, as this is within the velocity range favouring aeolian transport and deposition, i.e. high enough for transport to be initiated but allowing deposition of some sediment (Figure 17). Deposition in depressions and on the leeside of slopes is favoured, whilst some erosion occurs on highs. Grain size is intermediate.
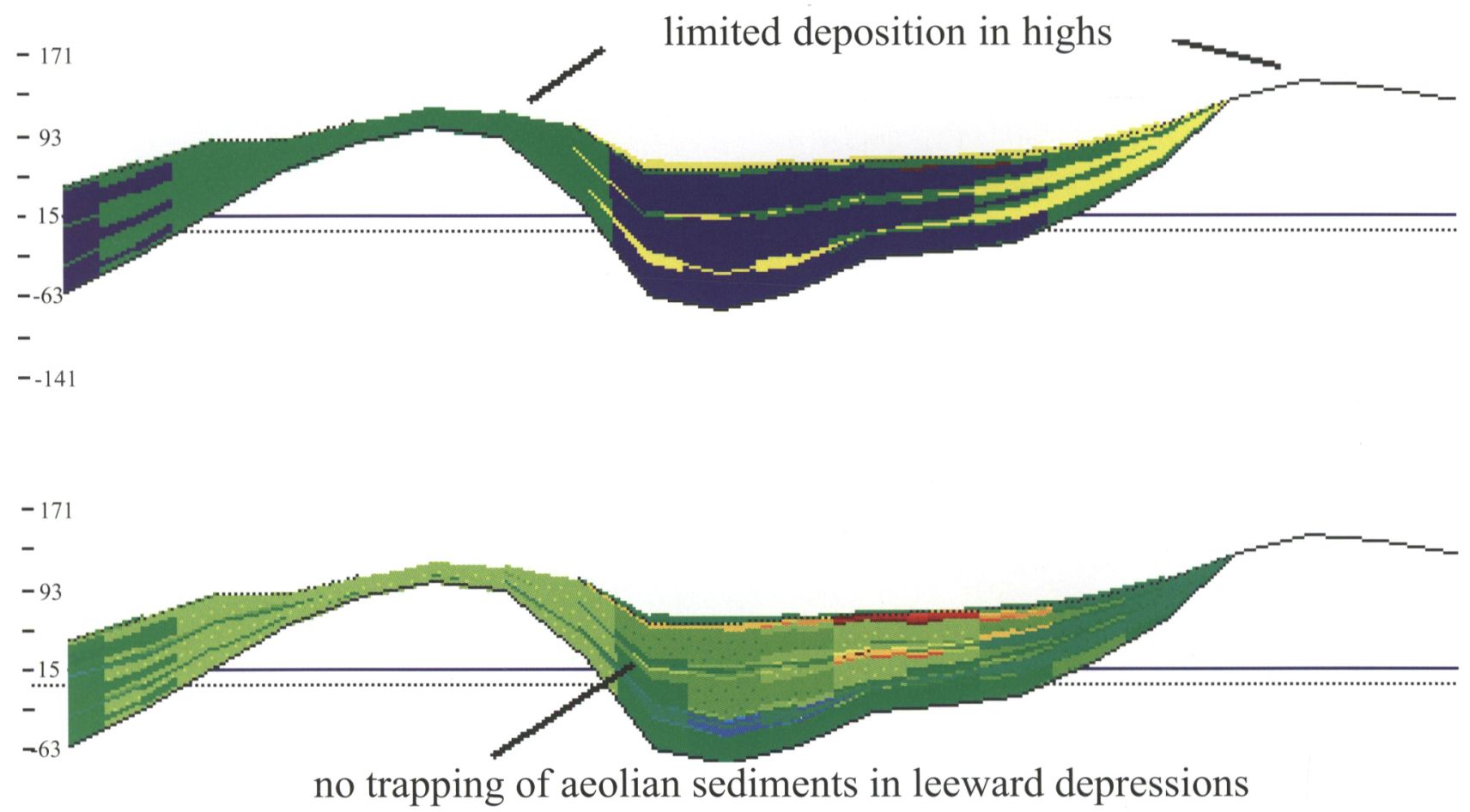

Fig. 16. Wind speed constant at $0 \mathrm{~m} / \mathrm{s}$. 1) Limited deposition on hight, 2) No trapping of aeolian sediments in leeward depressions. 


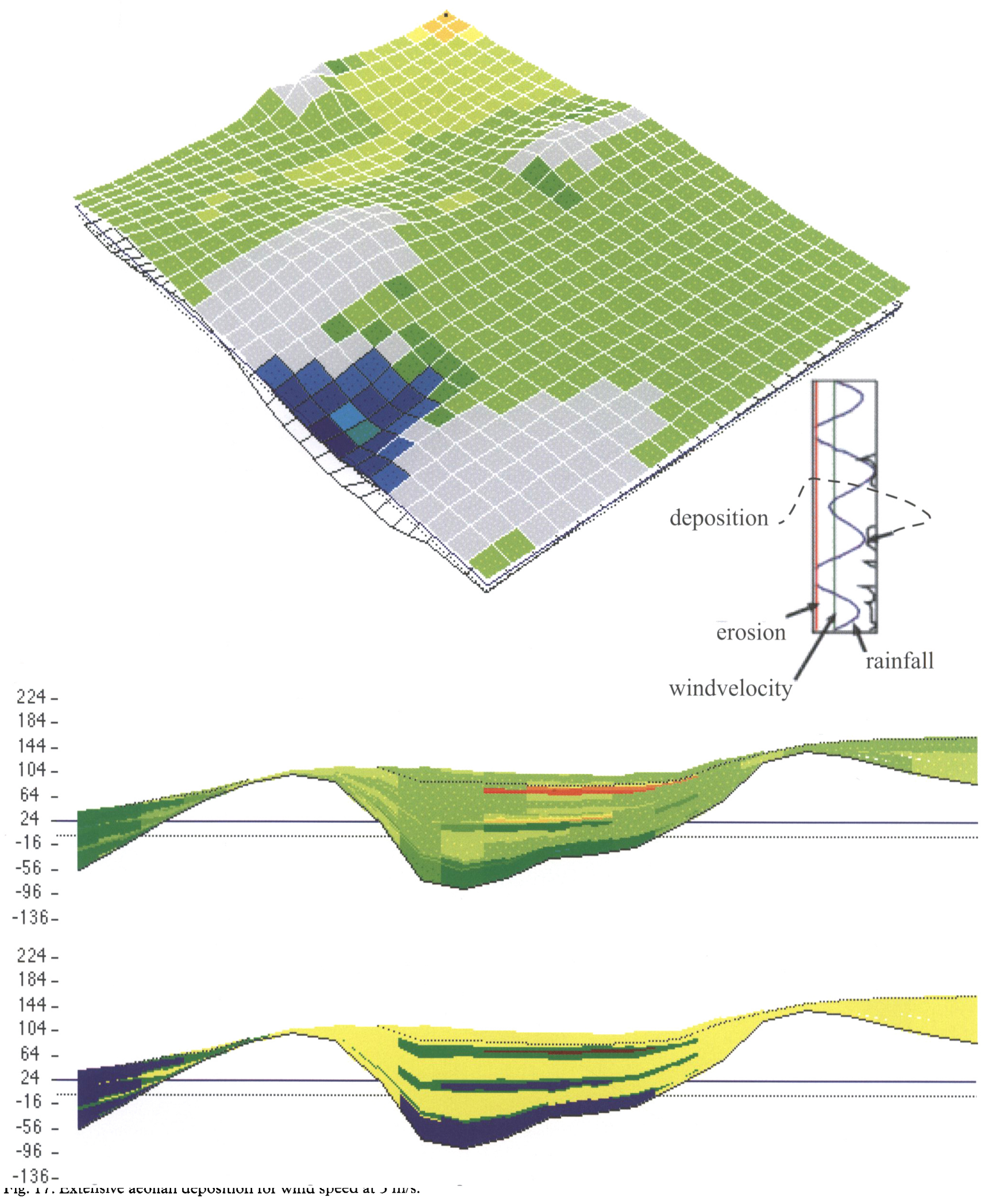

At higher velocities $(11 \mathrm{~m} / \mathrm{s})$, the dominant process is erosion. Deposition is restricted to velocity shadow zones in leeward locations and in topographic lows (Figure 18). Other areas exposed to the strong winds receive minor amounts of coarse to very coarse sediment, whilst highs and windward slopes are eroded.

Similar experiments involving rainfall show that a limited rainfall mainly affects fluvial transport and deposition, and also causes an increase in wind erosion due to a lowering of the water table. On the other hand, a high rainfall results in thick fluvial deposits and limited wind erosion. 


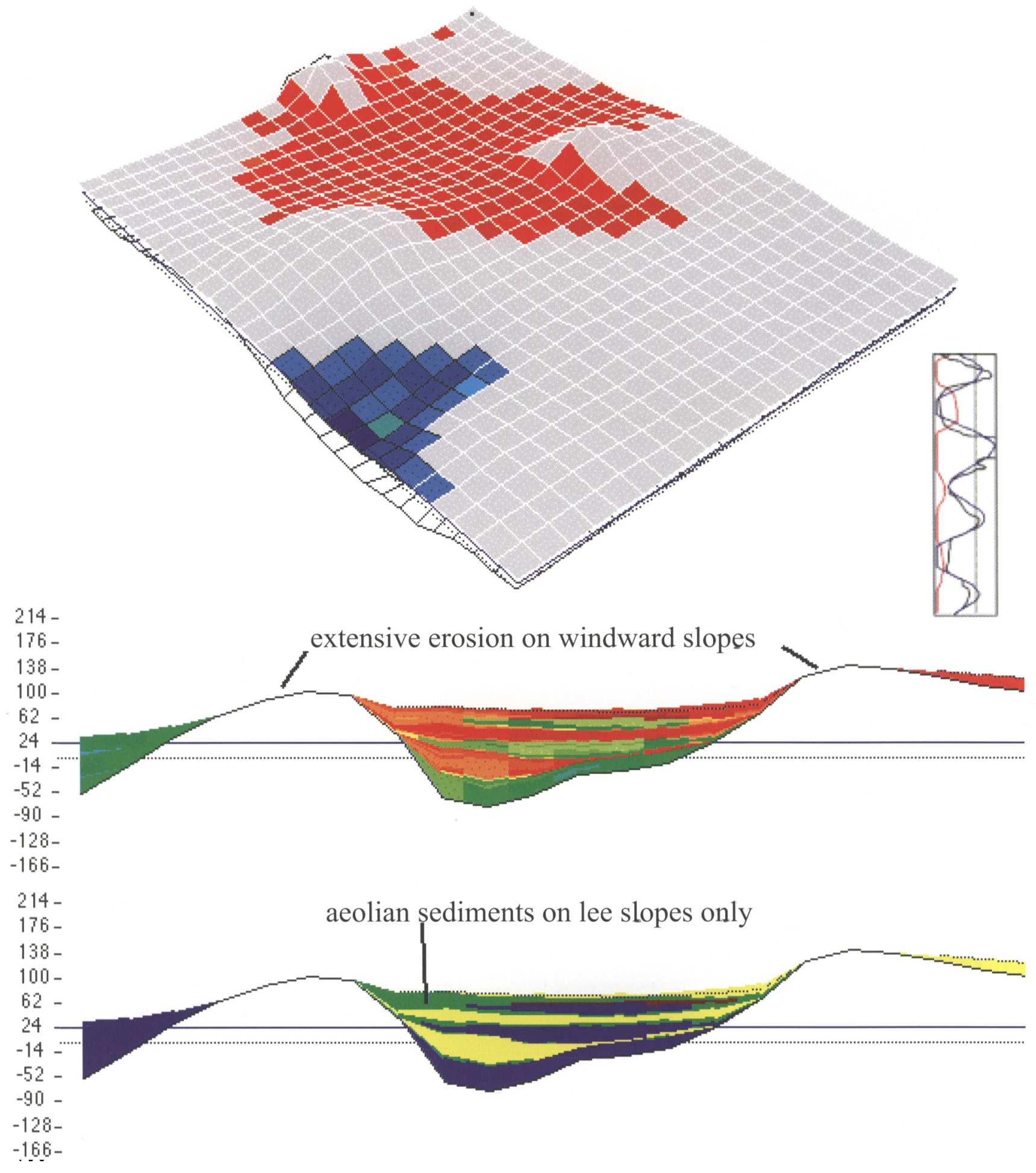

Fig. 18. Wind speed at $11 \mathrm{~m} / \mathrm{s}$. Erosion is dominant; deposition occurs on sheltered lee slopes only. 1) Extensive erosion on windward slopes, 2) Aeolian sediments of leeward slopes only.

The effect of subsidence and compaction

In the base case, subsidence was set at a constant rate of $0.035 \mathrm{~mm} / \mathrm{yr}$ on the proximal edge of the model and $0.05 \mathrm{~mm} / \mathrm{yr}$ at the distal edge of the model, with moderate compaction and isostatic compensation. The result is an exaggerated relief in comparison to the original surface. The main phase of differential subsidence due to isostacy occurs early in the simula- tion, effectively during the Lower Slochteren, when depressions are filled with sediment.

With subsidence, isostatic compensation and compaction turned off, sediments rapidly build above lake level and lake sediments are restricted to the base of the sequence at the distal edge (Figure 19). Because there is no isostatic compensation to accommodate 

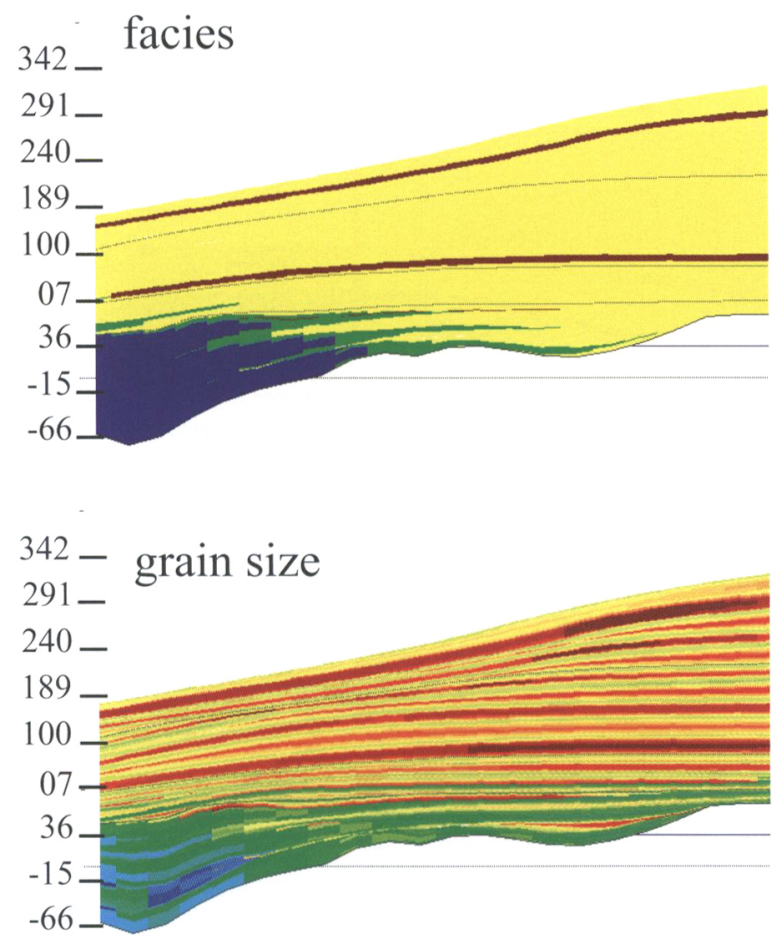

Fig. 19. 2D section with subsidence, isostacy and compaction OFF (strike section 20).

the sediments deposited, the initial topography is filled early and a planar surface is established.

In contrast, with subsidence, isostacy and compaction turned on, the lake bottom subsides at a pace that is equivalent to deposition. Lake sediments are thus represented throughout the succession (Figure 20). At the distal edge of the model, where subsidence is highest, lake sedimentation is continuous, without any breaks due to sub aerial exposure.

It is worthwhile noting that altering the subsidence and compaction variables, without any modification of the climatic variables, can generate very different architectures. Every effort should be made to ensure subsidence curves are as accurate as possible if realistic analogous architectures of the subsurface are to be generated.

\section{Final Results and Comparison}

In order to model the behaviour of the Rotliegend system under study, lake level, rainfall and wind velocity were tied to the generalized lake level curve for this area (Ladipo, 1997). Incorporating cyclicity at four frequencies provided variability. In addition, a topographic surface at top Carboniferous was supplied by NAM, along with a basic subsidence curve and wind directions.
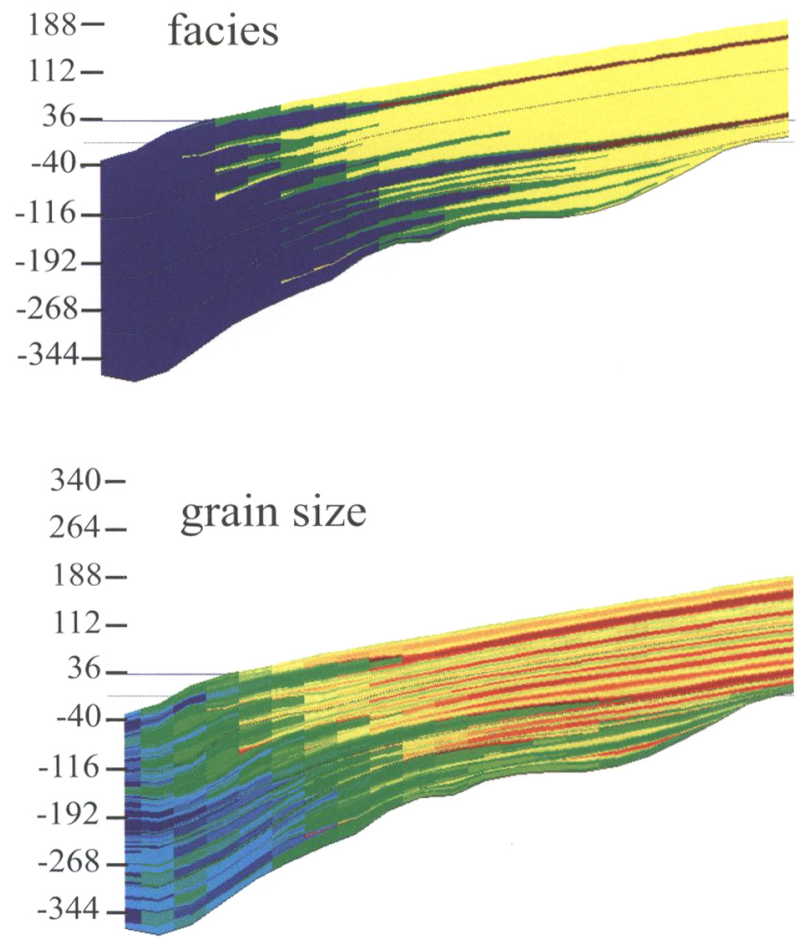

Fig. $202 \mathrm{D}$ section, as above but with subsidence, isostacy and compaction $\mathrm{ON}$.

The schematic section of the Upper Rotliegend Group in this area shows four alternations between wet and dry sediments (Figure 21). Fluvial wedges (orange) prograde from the SSE with coeval lacustrine transgressions (blue) from the NNW. Both fluvial and lacustrine sediments are replaced vertically by thick erg deposits (yellow), notably the Lower and Upper Slochteren Sandstone Members that together comprise the target reservoir facies. The AEOLIAN FUZZIM model of the area shows the same four-fold division (Figure 22), with similar replacement and northerly extensions of each successive erg phase and a comparable thickness differentiation between the Lower and Upper Slochteren Sandstones.

\section{Conclusion}

Important Parameters in Aeolian Modeling

From the experiments with 'AEOLIAN FUZZIM', it is possible to draw some general conclusions regarding the design of the controlling fuzzy system and the importance of the different parameters used.

As expected, the results are least sensitive to changes in the fuzzy sets. This is true providing, that the changes are within reasonable limits, i.e. the membership functions must make 'geological sense'. The results are more sensitive to changes in the rule base. The system works well in the NE Netherlands case, 


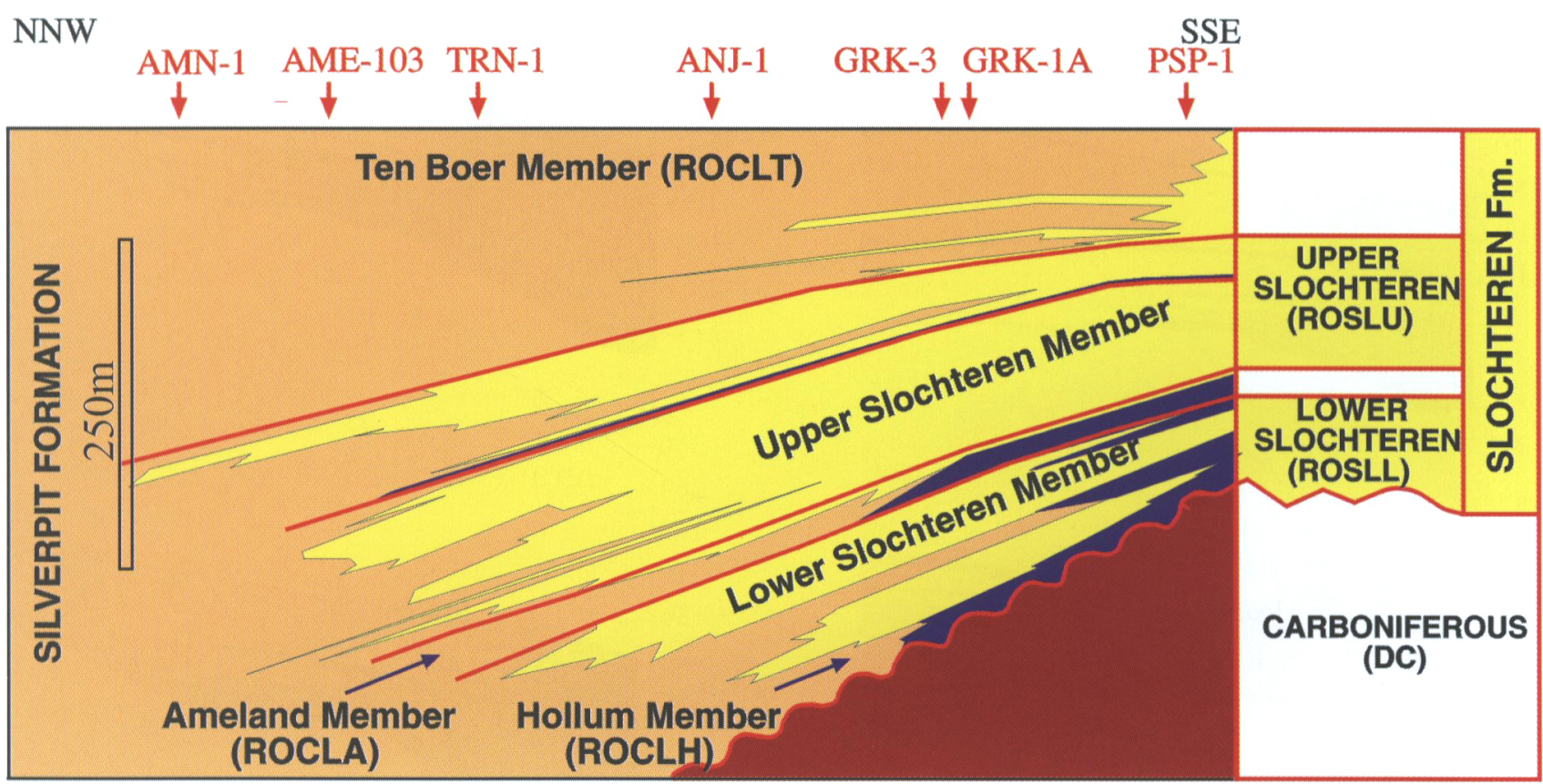

Fig. 21. Schematic section of Upper Rotliegend Group, NE Netherlands (see Fig. 1 for location).

and further study has indicated, that careful modifications make the system more generally applicable.

Of the input parameters, rainfall, which controls deposition during wet times, and wind velocity, which controls deposition and erosion during dry times, are the most important. A simple and very general aeolian model could be based only on these two input parameters. However, in order to capture local variations, the surface morphology and the wind direction have to be included. This will allow for differential de- position/erosion over the surface depending on local surface convexity/concavity and on the orientation of slopes relative to wind direction. The level of the water table can have a large impact locally, primarily on erosion, since it directly affects the stability of the surface.

Of the 'non-climatic' parameters, subsidence affects the results dramatically. High regional ('tectonic') subsidence rates may outpace sedimentation and result in successions dominated by lake and fluvial sedi-

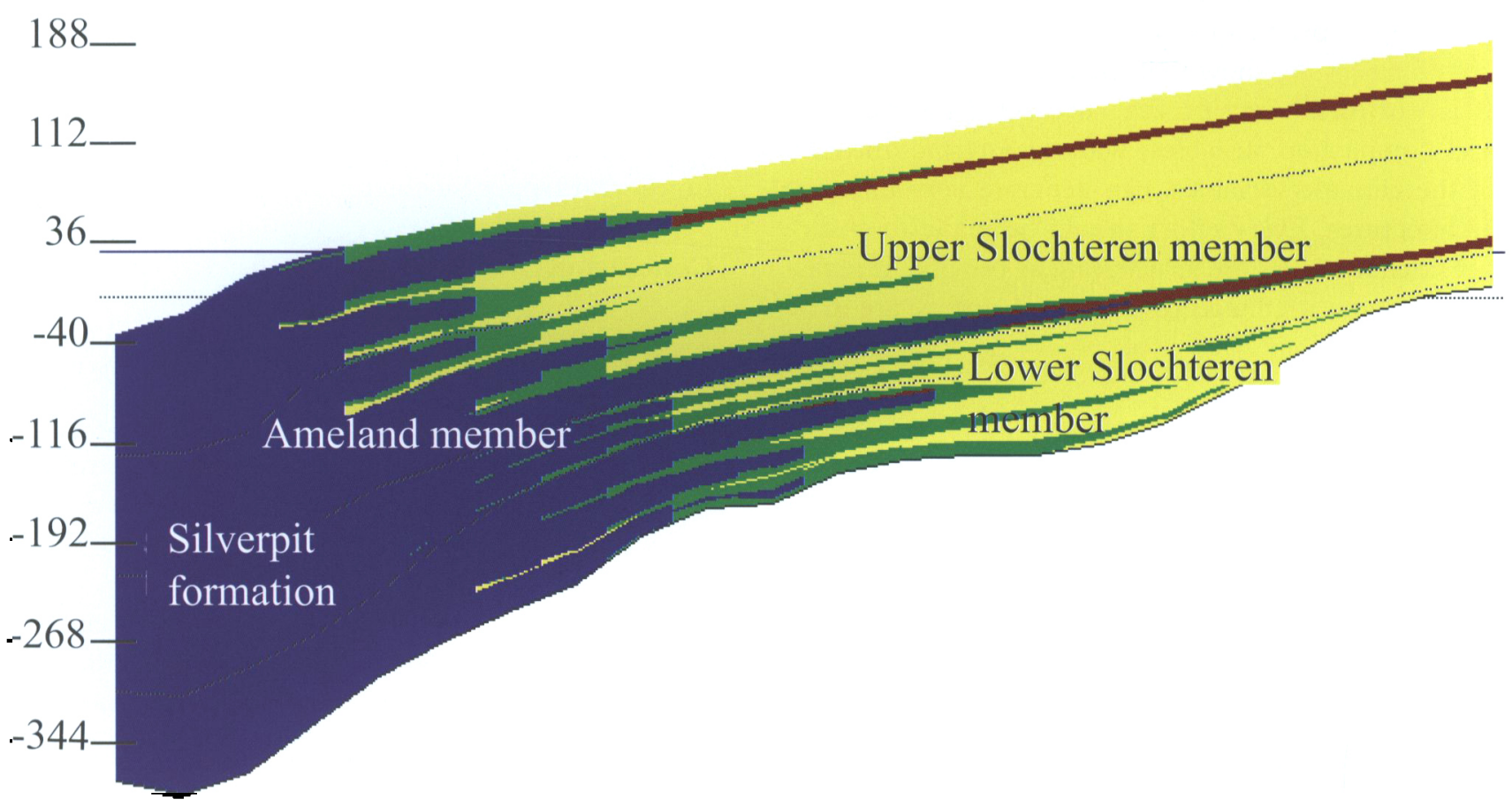

Fig. 22. Aeolian FUZZIM modelled architecture. 
ments, while low subsidence rates favour aeolian sediments. The differences in the models produced by varying subsidence within reasonable limits are striking. Similarly, variations in the degree of isostatic compensation, which has a direct effect on the surface morphology, can dramatically change the local distribution of deposition and erosion. This particularly affects low areas.

The subsidence model is thus of great importance. A detailed back-stripping procedure must be used to establish the regional as well as the local subsidence pattern, and to establish a reliable initial surface.

\section{Comparison of the Modeled and Real Architecture}

In the previous sections, the new forward model 'AEOLIAN FUZZIM' has been described. This model is based on an understanding of the controlling parameters for aeolian deposition. The model allows realistic prediction of aeolian and desert plain deposits. To test the quality of the prediction, the resulting model has been compared with the deterministic model of Ladipo (1997). Comparison of the model with the schematic architecture of the area shows convincing similarity although this is not unexpected as the temporal variation of the primary variables was tied to the local lake level curve. If the ranges or interaction between the variables did not capture the general processes of deposition and preservation within aeolian systems, however, the architecture would be significantly different. The fact that such similarity exists suggests, that both the ranges and interactions selected are appropriate for modeling the Rotliegend of this area. The results show that the distribution of aeolian reservoirs can be predicted by 3D forward modeling techniques and ultimately, the application of these programs should lead to better prediction of aeolian reservoirs.

\section{References}

Allen, J.R.L., 1994. Palaeowind: Geological Criteria for Direction and Strength. In: Allen, J.R.L., Hoskins, B.J., Sellwood, B.W., Spicer, R.A. \& Valdes, P.J. (eds.): Palaeoclimates and their Modeling - With Special Reference to the Mesozoic Era: 27-34.

Arens, S.M., 1996. Rates of Aeolian Transport on a Beach in a Temperate Humid Climate. Geomorphology 17: 3-18.

Bagnold, R.A., 1941. The Physics of Blown Sand and Desert Dunes, Methuen, London. 265pp.

Blakey, R.C. et al., 1988. Synthesis of Late Palaeozoic and Mesozoic Eolian Deposits of the Western Interior of the United States. Sedimentary Geology 56: 3-125.

Breed, C.S., Fryberger, S.G., Andrews, S., McCauley, C., Lennartz, F., Gebel, D. \& Horstman, K., 1979. Regional studies of sand seas, using LANDSAT (ERTS) imagery. In: McKee,
E.D.(ed.): A Study of Global Sand Seas. Professional Paper U.S. Geological Survey 1052: 305-397.

Cooke, R.U., Warren, A. \& Goudie, A.S., 1993. Desert Geomorphology. UCL Press, London: 526.

De Jongh, R., 1996. STRATAGEM., a 2D stratigraphic forward modeling package. Krefeld 1996 (abstract)

Dawson, P.J and Marwitz, J.D., 1982. Wave Structures and Turbulent Features of the Winter Airflow in Southern Wyoming. Geol. Soc. Am. Sp. Paper 192: 55-63.

Fischer, A.G. and Bottjer, D.J., 1991. Orbital Forcing and Sedimentary Sequences. Journal of Sedimentary Petrology 61/7: 1063-1069.

Fonseca, C., 1999. STRATAGEM - Can 2D modeling of a 3D world still be state-of-the-art? Tronheim August 1999 (abstract)

Fryberger, S.G. \& Ahlbrandt, T.S., 1979. Mechanism for the Formation of Aeolian Sand Seas. Zeitschrift fur Geomorphologie NF 23: 440-460.

Glennie, K.W., Pugh, J.M. \& Goodall, T.M., 1994. Late Quaternary Arabian Desert Models of Permian Rotliegend Reservoirs. Exploration Bulletin 274: 1-19.

Haq, B.U., Hardenbol, J. and Vail, P.R., 1988. Mesozoic and Cenozoic Chronostratigraphy and Cycles of Sea-Level Change. In: Sea-Level Changes - An Integrated Approach, SEPM Sp. Publ. 42. ISBN 0-918985-74-9.

Imbrie, J. and Imbrie, K., 1979. Ice Ages: Solving the Mystery: Short Hills, NJ. Harvard University Press: 224pp.

Kocurek, G. \& Havholm, K.G., 1993. Eolian Sequence Stratigraphy - A Conceptual Framework. AAPG Memoir 58: 393-409.

Kutzbach, J.E. \& Ziegler, A.M., 1994. Simulation of Late Permian Climate and Biomes with an Atmosphere-Ocean Model: Comparisons with Observations. In: Allen, J.R.L., Hoskins, B.J., Sellwood, B.W., Spicer, R.A. \& Valdes, P.J. (eds.): Palaeoclimates and their Modeling - With Special Reference to the Mesozoic Era: 119-132.

Ladipo, K.O., 1997. Cyclostratigraphy of the Upper Rotliegend Slochteren Formation, NE Netherlands: A Genetic Unit Subdivision and Correlation of Fluvio-Aeolian Facies. In: Barren Sequences Special Issue, SIEP 97-7021.

Lancaster, N., 1983. Controls on Dune Morphology in the Namib Sand Sea. In: Ahlbrandt, T.S. \& Brookfield, M.E. (eds.): Eolian Sediments and Processes. Elsevier: 261-289.

Loope, D.B., 1995. Episodic deposition and preservation of eolian sands: A late Palaeozoic example from Southeastern Utah. Geology 13: 73-76.

Mainguet, M., 1978. The Influence of Trade Winds, Local Air Masses, and Topographic Obstacles on the Aeolian Movement of Sand Particles and the Origin and Distribution of Dunes and Ergs in the Sahara and Australia. Geoforum 9: 17-28.

Marsh, N.D. \& Ditlevsen, 1997. Observation of Atmospheric and Climate Dynamics from a High Resolution Ice Core Record of a Passive Tracer over the Last Glaciation. Journal of Geophysical Research 102 (D10): 11219-11224.

Nickling, W.G., 1988. The Initiation of Particle Movement by Wind. Sedimentology 35: 499-511.

Nordlund, U., 1996. Formalizing geological knowledge with an example of modeling stratigraphy, using Fuzzy logic. J.Sedimentary Res. 66: 689-698.

Perlmutter, M.A. \& Matthews, M.D., 1989. Global Cyclostratigraphy - A Model. In: Cross, T.A.(ed.): Quantitative Dynamic Stratigraphy. Prentice Hall: 233-260.

Sarnthein, M., 1978. Sand Deserts during Glacial Maximum and Climatic Optimum. Nature 272: 43-46.

Sarnthein, M., Tetzlaff, G., Koopman, B., Wolter, K. \& Pflaumann, U., 1981. Glacial and Interglacial Wind Regimes over the Eastern Subtropical Atlantic and Northwest Africa. Nature 293: 193-196. 
Thomas, D.S.G. \& Shaw, P.A., 1991. 'Relict' Desert Dune Systems: Interpretations and Problems. Journal of Arid Environments 20: 1-14.

Wiggs, G.F.S., Thomas, D.S.G. \& Bullard, J.E., 1995. Dune Mobility and Vegetation Cover in the Southwest Kalahari Desert. Earth Surface Processes and Landforms 20: 515-529.

Williams, S.H. \& Lee, J.A., 1995. Aeolian Saltation Transport Rate: an Example of the Effect of Sediment Supply. Journal of Arid Environments 30: 153-160.

Wilson, I.G., 1971. Aeolian Bedforms - Their Development and Origins. Sedimentology 19: 173-210.

Wilson, I.G., 1973. Ergs. Sedimentary Geology 10: 77-106.

Zadeh, L.A., 1965. 'Fuzzy Sets', Information and Control 8: 338353. 